\title{
Vibration Signals Based Bearing Defects Identification Through Online Monitoring Using LABVIEW
}

\author{
Maheswari Chennippan $^{1 *}$, Priyanka E. Bhaskaran ${ }^{1}$, Ibrahim Sherrif K. Adhulrasheed ${ }^{2}$, Thangavel Subramaniam ${ }^{1}$, \\ Ramani Govindasamy ${ }^{3}$ \\ ${ }^{1}$ Department of Mechatronics Engineering, Kongu Engineering College, Perundurai 638060, India \\ ${ }^{2}$ Department of Mechanical Engineering, Kongu Engineering College, Perundurai 638060, India \\ ${ }^{3}$ Department of Electrical \&Electronics Engineering, Nandha Engineering College, Perundurai 638060, India
}

Corresponding Author Email: maheswari@kongu.ac.in

https://doi.org/10.18280/jesa.530204

Received: 2 February 2020

Accepted: 16 March 2020

\section{Keywords:}

fault identification, ball bearing, online monitoring, Programmable Logic Controller (PLC), LABVIEW

\begin{abstract}
Rolling element bearing is one of the important components in rotary machines. Although a significant quantum of work has been done on bearing defect monitoring, estimation of defect size in bearing elements is still a challenge. Vibration signals resulting from rolling element bearing defects, present a rich content of physical information, the appropriate analysis of which can lead to the clear identification of the nature of the fault. The proposed research work is examined under laboratorial set-up keeping rotating speed and or load variation remains unchanged. Hence this paper represents the online monitoring approach of identifying outer, inner race and ball defects in the ball bearing based on the location, count and size of the defects by incorporating PLC with LABVIEW platform. A monitoring tool acquires experimental data from a bearing vibration control test rig. An accelerometer captures the signal from the bearing outer ring then it is processed using PCI-4451 National Instruments data acquisition board and LabVIEW software. To analyze the peak value of the vibration signals during faults, the following $0.5,1$ - and 2-mm defect size were undertaken. Through real-time experimentation the minimum and maximum range of vibration amplitude values were observed by varying the defect counts as single and multi-nature basis on three zones like inner, outer race and ball of the bearings. Its experimental numerical results reveal that of ball bearing without defects holds values between $10 \mathrm{mV}$ to $16 \mathrm{mV}$ and it also confirms that the ball defects hold higher amplitude vibration on comparison with defects on the inner and outer race vibration signals.
\end{abstract}

\section{INTRODUCTION}

Fault diagnosis is an important process in condition monitoring of machine systems and different mechanical components like ball/rolling bearings. Vibration based fault detection and diagnosis analysis is a well-established field in machine or monitoring supervision. Research has been carried out in the last years for the development of various methods for bearing fault detection and diagnosis [1]. These methods can be classified into time domain, frequency domain, timefrequency domain, higher order spectral analysis, neuralnetwork and model-based techniques. Components that often fail in rolling element bearing are outer race, inner race and the ball. The bearing defects generate a series of impact pulses every time a running ball passes over the surfaces of the defects. Each such impulse excites a short transient vibration in the bearing and the mechanical structure at its natural frequencies [2]. These impacts recur at bearing characteristic frequencies, which are estimated based on the running speed of shaft, the geometry of the bearing, and the location of the defect Ball bearing and its component features with labeling are shown in the Figure 1. However, the selection of exact band of frequency for filtering and to reject the unwanted frequencies is very challenging for dynamic, non-stationary behavior of the motor [3]. Additionally, it is quite needful to use the envelope analysis for the transient properties of raw vibrational amplitude modulation in the case of the identification of rotating element bearing fault signatures.

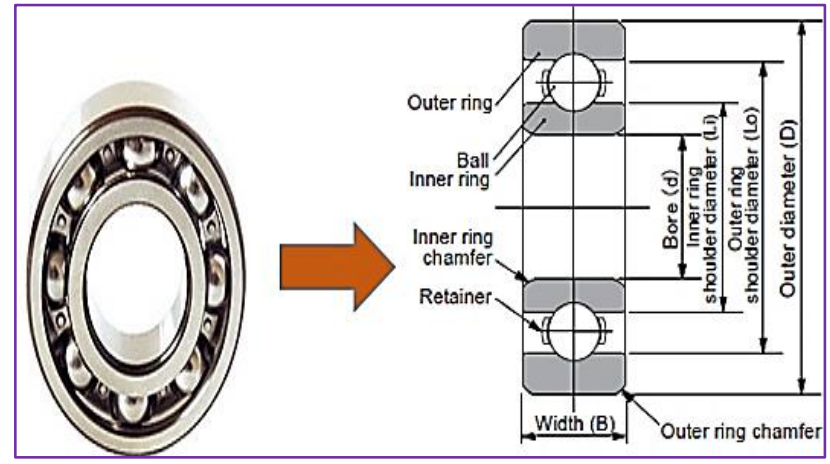

Figure 1. Ball bearing structure with its essential parts

Using the envelope analysis for induction motor failures, the bearing characteristic fault frequencies can be easily identified. Based on this, the recognition of local fault signatures in a rolling element can be analyzed and a fault pattern can be distinguished. Perfect and suitable analysis of working and mounting conditions of the sensors is highly required to interpret exact spectrum modulation for the analysis of 
vibrational amplitudes [4]. The most occurring appropriate analysis of vibration signatures for bearings deals with the simple and common methods of time, frequency as well as time-frequency domain analysis. The literature analysis shows that by building a drive reaction wavelet by utilizing constant wavelet change to remove the element of vibration signals. They proposed two strategies, to be specific, the scale-wavelet power range examination and the auto-relationship investigation of time-wavelet power range for recognizing the deficiencies of roller bearing and recognizing the deficiency designs [5]. Further researcher introduced a sign handling calculation dependent on multi-scale wrapping spectrogram for vibration signal examination. This strategy was assessed for restricted auxiliary deformities and tentatively discovered fruitful. Also, to build up a logical model to anticipate the impact of a restricted imperfection ready bearing vibrations by considering the contact between the ball and the races as nonstraight springs. For profound score metal ball, they got numerical outcomes by utilizing the model which yielded both the recurrence and the increasing speed of vibration parts of the bearing for reproducing the imperfection [6].

Zakhezin and Malysheva identified fatigue crack vibration diagnosis. The diagnosis of fatigue cracks in a rotor system is based on the investigation of vibration signals measured in bearing housings with fatigue cracks of various depths. Wang et al. addressed the vibration response of spalled rolling element bearings, simulations and signal processing techniques to monitor spall size and investigate seeded fault vibration signatures at different speeds. The acceleration signals resulting from the rolling element's entry into and departure from the spall are of various natures [7]. The advantage of accelerometers is that they have a wide dynamic range and a broad frequency range for measuring vibration. Ma et al. named the vibration response of the proposed fault signal model and the measurement equation of the fault signal is derived by dynamic and kinematic analysis. It is also evident from previous research works that researchers studied the problems of bearing dynamics and various methods of detecting bearing defects. Researchers have recently examined the techniques used to examine bearings defects from the bearing's vibration signals. The received vibration signals vary for each of the defects [8]. The use of an accelerometer system has the advantage of having a wide range of measuring vibrations. The vibration obtained for the outer race and the faults of the inner race are different, as the outer race and inner race defect positions change. If the fault width is small and the resulting signal is low which increases with an increase in the defect's distance. The acquired signals are stored in wavelet technique. Measured with the manufactured defect bearings, the real bearing signal is measured [9].

Further, Laboratory Virtual Instrumentation Engineering Workbench (LabVIEW) is a graphical programming environment based on the concept of data flow programming. It is gaining its popularity as a graphical programming language especially for data acquisition and measurement. This is due to the vast array of data acquisition cards and measurement systems, which can be supported by the LabVIEW as well as the relatively easy by which advanced software can be programmed [10]. LabVIEW features an easyto-use graphical programming environment by integrating these powerful Virtual Instrument technology products in a flexible laboratory environment with enormous possibilities of expansion and experimentation. The LabVlEW full development system features the analysis library. The function in this library is called virtual Instruments (VIS). These VIS allow us to use classical digital processing algorithms without writing a single line of code. The LabVIEW block diagram approach and the extensive set of analyhcal VIS simplify the development of analysis applications [11].

Hence in the presented research work, the ball bearing defects are observed by taking location, sizes and count of the defects on the inner, outer race and ball of the bearings by executing vibration analysis with the utilization of LABVIEW platform. The summary of the paper as follows: section 2 contains the characterization of ball bearing defects, section 3 shows the undertaken experimental setup with technical specifications. Section 4 reveals the real-time vibration analysis on the defects by taking count, size and location of the defects and finally section 5 enumerates the data logging and online monitoring and identification of defects in the ball bearings.

\section{CHARACTERIZATION OF BALL BEARING DEFECTS}

Bearings are usually categorized into two main groups, i.e., internal and external rotating race bearings. The key cause of the harm is excessive noise in spinning machinery. Defaults in ball bearings may be classified as localized and distributed. The localized defects include cracks, holes, and spalls on rolling surfaces caused by fatigue. The other types, i.e. distributed defects, include roughness of the surface, waviness, and misaligned races and rolling elements off scale. The mechanical damage can be responsible for these defects [12]. Therefore, the analysis of the vibrations created by these defects is important for both quality inspection and condition monitoring. The specific defect size considered for the analysis on the bearing breeds and ball are $0.5 \mathrm{~mm}, 1 \mathrm{~mm}$, and $2 \mathrm{~mm}$. In the inner race, outer race, cage, ball and combination of these parts the defect in the rolling element that occur.

The failure occurs in the bearing outer and inner rings are called as defect in outer and inner race. These failures may occur due to dynamic load acting on the bearing. The failure in the ball is missing up the ball bearing or ball broken. Shock spacing corresponds to twice characteristic ball spin frequency and is modulated with a period corresponding to one cage revolution. The ball failure may occur due to fatigue load acting on the bearing. Multi dents are the combination of more than one defect on the bearing parts with different defect sizes and at different angles [13]. Multi dents are considered as two dents and three dents. The two dents are considered at $90^{\circ}$ having the combination of $0.5 \mathrm{~mm}, 1 \mathrm{~mm}$ and $2 \mathrm{~mm}$ in inner race, ball and outer race of the bearing. The three dents are considered at $120^{\circ}$ having the combination of $0.5 \mathrm{~mm}, 1 \mathrm{~mm}$ and $2 \mathrm{~mm}$ in inner race, ball and outer race of the bearing. This research work is approached by the vibration analysis technique in bearing to monitor the condition using accelerometer with PLC.A method is devised for real time condition monitoring of bearings to identify the different defects occurring in the ball bearings due to defects in the bearing [14]. The defect in the bearings is produced artificially and used in the experiment for acquiring the signal. Figure 2 shows the undertaken defect types for real-time experimentation. 


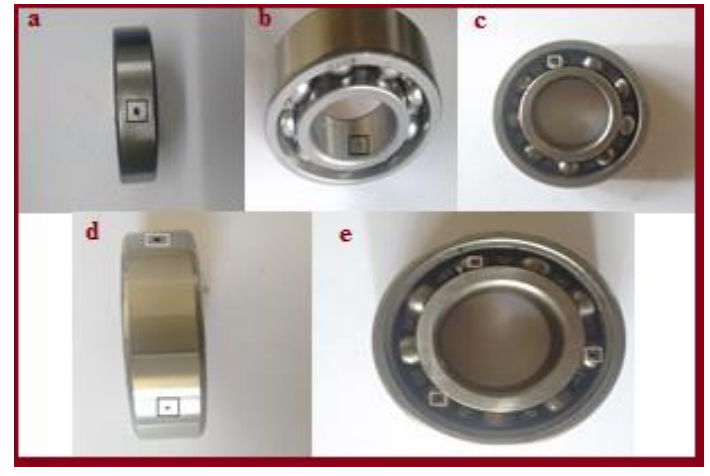

Figure 2. a). One single outer-race flaw, b). Single internalrace flaw, c). Ball flaw, d). Double dents in outer line, e).

Multi flaws in ball

\section{EXPERIMENTAL SETUP AND SPECIFICATIONS}

Figure 3 demonstrates an advanced research rig designed to predict ball bearings defects. The test rig consists of a rotor shaft that is balanced on two bearings. The shaft is driven by a universal motor coupled by a geared coupling. The shaft is 110 $\mathrm{cm}$ length and diameter are $25 \mathrm{~mm}$. The distance between two ball bearings is $620 \mathrm{~mm}$. At driver end and at free end a ball bearing is mounted.6205Z model ball bearing has been used for analysis. The ball bearing specifications are shown in Table 1 . The ball bearing is tested by fixing it to the setup. From the bearing housing the vibration signal is obtained [15]. On the bearing housing mounting point, the accelerometer sensor is installed in which Micro Logix 1100 PLC is interfaced to acquire bearing processed signals.
Vibration signals are taken for good bearing and defective bearings. The signal is taken for analysis through PLC and the values are recorded in spreadsheet using Factory talk view studio. The vibration signals of the faulty bearings are contrasted with successful bearing vibration signals to diagnose fault due to defect in the bearing. Initially good bearing is fitted in both drive and driven end as well as recording vibration signals. Then the driven end bearing is removed and fitted with defective bearing. The vibration signals are acquired using the accelerometer [16-18]. Similarly, the other defected bearings are changed in drive end and vibration signals are to be acquired. Finally, the vibration signals are processed and compared with good bearing for identifying the fault. The ball bearing and accelerometer utilized for experimental analysis specification is given in Table 1.

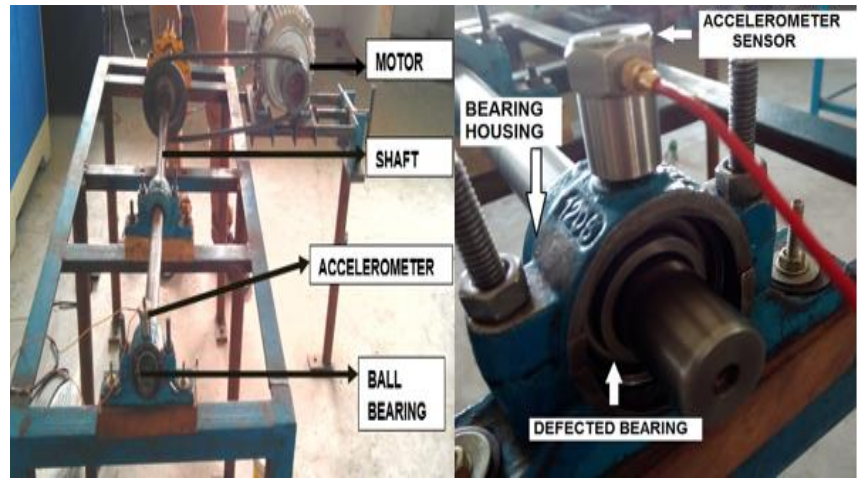

Figure 3. Experimental Setup with accelerometer fixed on bearing housing unit

Table 1. Ball bearing and accelerometer specifications taken for testing

\begin{tabular}{cccc}
\hline \multicolumn{2}{c}{ Ball Bearing } & \multicolumn{2}{c}{ Accelerometer } \\
\hline Make & SKF 6205Z & Model No & IPA PG114MO \\
Number of balls & 9 & Sensitivity & $10-500 \mathrm{mV} / \mathrm{m} / \mathrm{sec}^{2}$ \\
Outer diameter & $52 \mathrm{~mm}$ & Measuring range & $\pm 500 \mathrm{~g}$ \\
Inner diameter & $25 \mathrm{~mm}$ & Operating frequency/ Temperature range & $10 \mathrm{~Hz}$ to $2000 \mathrm{~Hz} / 0^{\circ}$ to $60^{\circ} \mathrm{C}$ \\
Ball diameter & $8 \mathrm{~mm}$ & Case Material/Weight & Stainless Steel/200gms \\
\hline
\end{tabular}

\subsection{Feature extraction on vibration signals}

The wavelet technique provides a time-scale information in the signal, and it can efficiently detect the transients. The Continuous Wavelet Transform (CWT) is used in timefrequency analysis that decomposes a signal in both time domain and frequency domain simultaneously [19]. The CWT can be defined as:

$$
\operatorname{CWT}(a, b)=1 / \sqrt{a} \int_{\infty}^{-\infty} x(t) \varphi^{*}\left(\frac{t-b}{a}\right) d t
$$

where, a represents the scale parameter, $b$ represents the translation parameter, $\varphi$ represents the 'mother' wavelet and $\varphi^{*}$ is the complex conjugate of $\mathrm{w}$. The CWT and its computation may consume significant amount of time and resources, depending upon the resolution required. The Discrete Wavelet Transform (DWT), which is based on sub band coding is found to yield a fast computation of wavelet transform is a discrete form of the CWT [20]. It adopts the dyadic scale and translation to reduce computation time. The DWT can be defined as:

$$
\operatorname{DWT}(a, b)=1 / \sqrt{2^{j}} \int_{\infty}^{-\infty} x(t) \varphi^{*}\left(\frac{t-2^{j} k}{2^{j}}\right) d t
$$

where, $2^{j} k$ and $2^{j}$ represent the scale parameter and the translation parameter respectively. In this $\mathrm{j}$ and $\mathrm{k}$ are integers. The functions and scales are represented as an approximations value. The curves of scale functions can be modified by the scale parameter, which is the inverse ratio to frequency. The DWT analysis is made by passing the signal through a series of filters. The original signal $\mathrm{x}(\mathrm{t})$ can be defined as:

$$
x(t)=A_{j}+\sum_{j \leq j} D_{j}
$$

where, $A_{j}$ and $D_{j}$ represent the approximation and the detail signals of the $j t h$ level. It is usually utilized to quantitatively describe the impact level of vibration signal due to its sensitivity to impact signal [21]. As for discrete signal, its expression can be expressed by: 


$$
k=\frac{1}{N} \sum_{i=1}^{N}\left(\frac{x_{i}-\mu}{\sigma}\right)^{4}
$$

where, is $x_{i}$ sampling signal, $\mu$ is the mean of signal, and $\sigma$ is standard deviation. By focusing on a limited number of signal components, that is, rotational frequency, fault characteristic frequency, and its frequency multiplication which includes super harmonic and subharmonic frequency components. Furthermore, other components can be seen as noise to be eliminated [22-24].

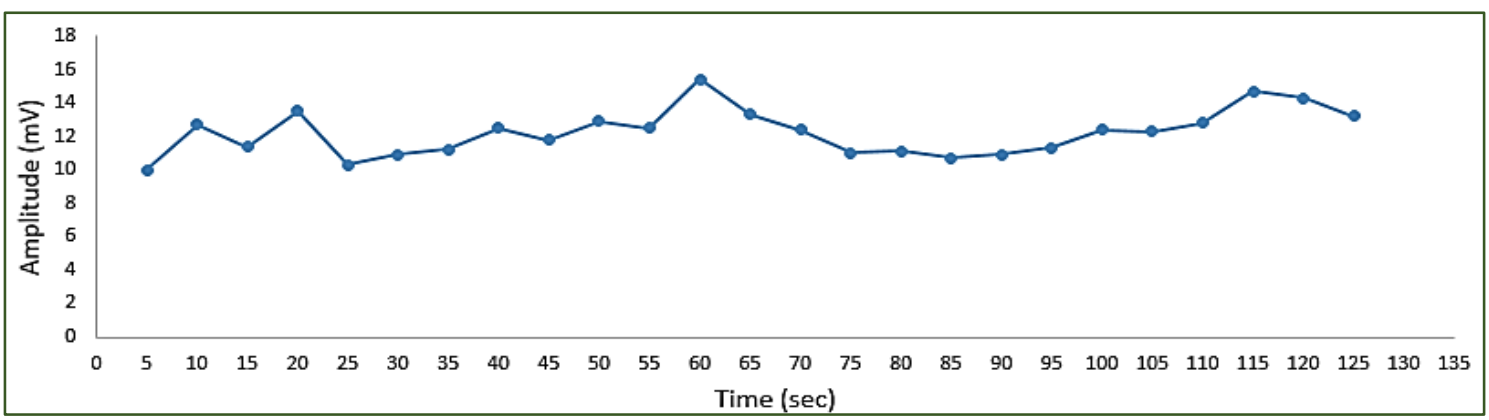

Figure 4. Vibration effects on good bearing

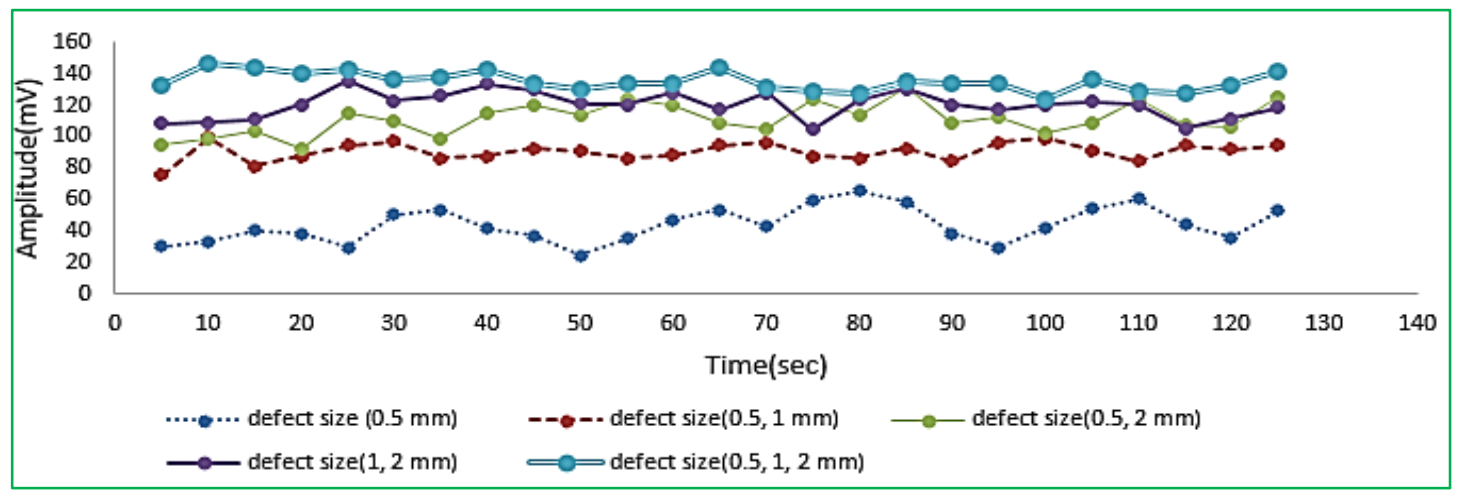

Figure 5. Combination of vibration signals of inner defects

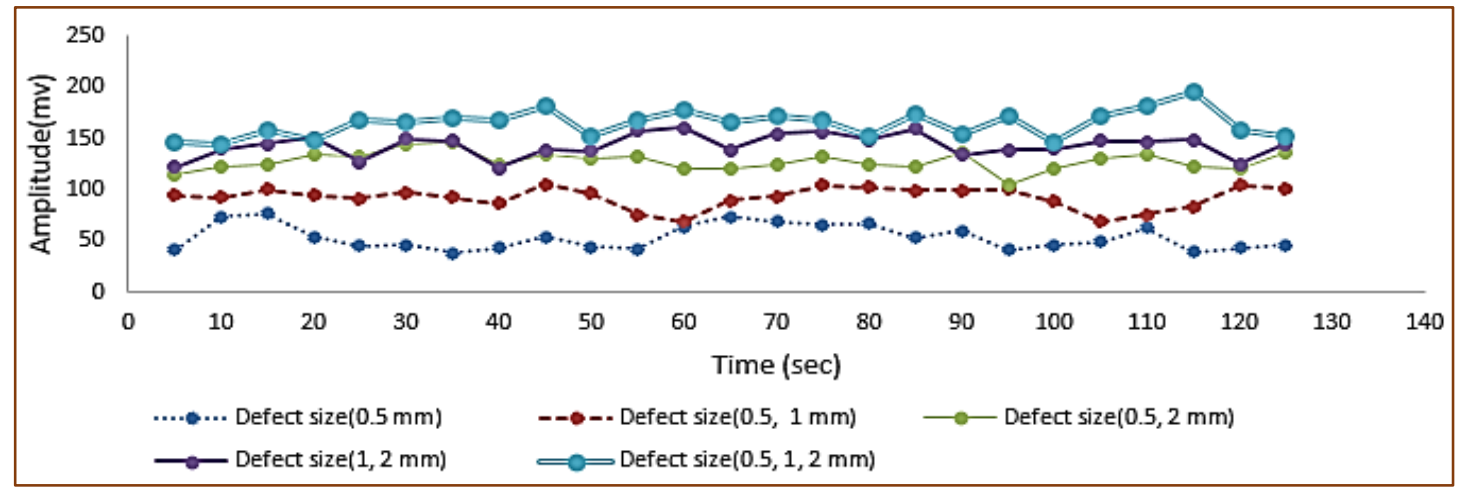

Figure 6. Combination of vibration signals on outer defects

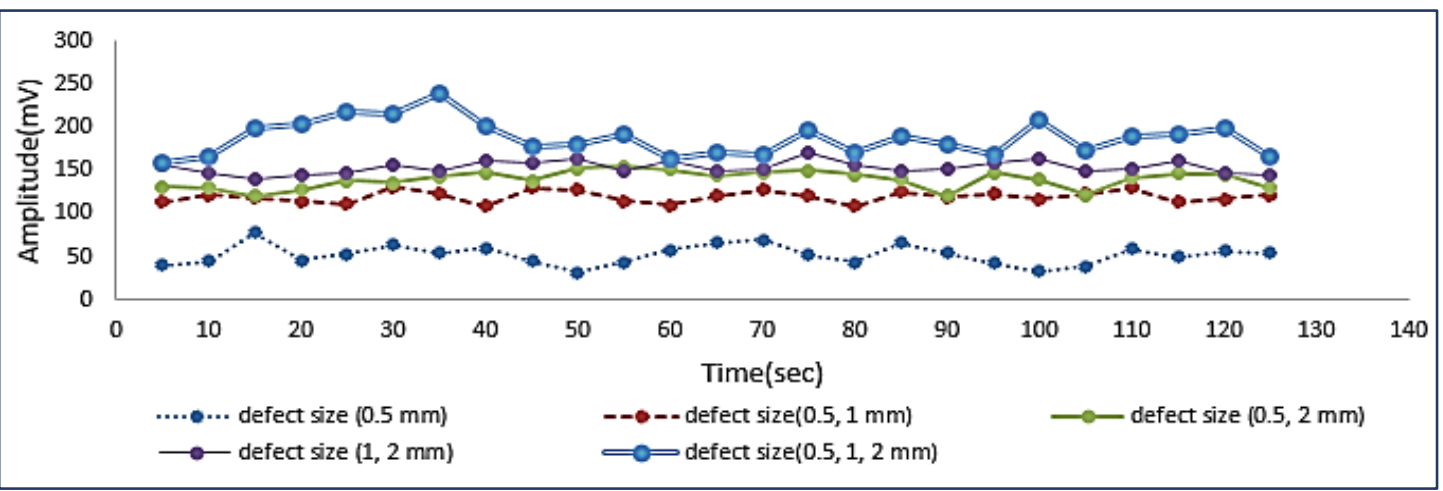

Figure 7. Combination of vibration signals on ball defects 


\section{REAL-TIME ANALYSIS OF VIBRATION SIGNALS ON DEFECTS IDENTIFICATION}

In the real-time experimentation, the ball-bearings are subjected to different validations by varying the depth of the defects and the count of the defects with respect to its locations on the inner, outer race and balls of the bearings. Each location vibration signals are measured by varying the depth from $0.5,1$ and $2 \mathrm{~mm}$ respectively. The set of vibration signals for good bearing in combination of multi dents in ball bearing are recorded. Then it is analyzed by comparing the vibration signals produced by good bearing.

\subsection{Analysis with good bearing}

Vibration signal obtained for good bearing is shown in the Figure 4. The vibration signals are taken for 25 samples at an interval of 5 Seconds. The obtained values range between $10 \mathrm{mV}$ and $16 \mathrm{mV}$. The peak of the vibration signals is $16 \mathrm{mV}$, $14.5 \mathrm{mV}$ and $13.2 \mathrm{mV}$. The measurement is taken as the benchmark values for the further comparison with defected bearing. The vibration signals obtained for the different defect size of inner, outer races and balls are compared to provide the range of values separately for inner race, outer race and the ball defect in the ball bearing.

\subsection{Comparing vibration signals on inner race defects}

Vibration signals obtained from the inner race of the ball bearing holding different depths of defects are compared by gradually increasing the defects counts in order to observe the maximum range of the amplitude. It is inferred that the vibration signals vary with increase in depth size in inner race defect. The Figure 5 shows the peak of the vibration is obtained for the inner race defect with $0.5,1$ and $2 \mathrm{~mm}$ defect size which is $147 \mathrm{mV}$. In addition to that, the peak value of single defect in the inner race of the bearing is $63.5 \mathrm{mV}$. The peak value of the combination of the double defects are $69.8 \mathrm{mV}$ and $140.8 \mathrm{mV}$. The peak value for the three defects on the inner race is $147.2 \mathrm{mV}$. Using this range of vibration signals, the defect in the inner bearing can be classified as the single, double and multi defect. Hence with the minimum and maximum range of amplitude of inner race defects falls within the values of $63.5 \mathrm{mV}$ and $147.2 \mathrm{mV}$ respectively.

\subsection{Comparing vibration signals on outer race defect}

Similarly, the vibration signals analysis is carried out for the observation of outer race defects by making single, double and multiple defects with various depths in the ball bearing. It also confirms that the amplitude of vibration gets increased when the depth of the defect gets increased. The Figure 6 shows the peak of the vibration signal is obtained for the outer race defect with $0.5,1$ and $2 \mathrm{~mm}$ size. It exposes that the defect in the outer bearing causes higher vibration as compared to inner race defects of ball bearing. The vibration signal value of the single defect in outer bearing lies around $66 \mathrm{mV}$. The vibration signal value of double defects in outer race ranges between 75 $\mathrm{mV}$ to $161 \mathrm{mV}$. The vibration signal value for the three defects on the outer race ranges between $144 \mathrm{mV}$ to $196 \mathrm{mV}$. Hence the minimum and maximum amplitude values of the outer race defects are constrained around $66 \mathrm{mV}$ and $196 \mathrm{mV}$ correspondingly.

\subsection{Comparing vibration signals on ball defects}

In the analysis on the ball is entirely different from inner and outer race experimentation. Because, the vibration of the ball defect reaches higher values because the ball rotates continuously with the inner race and the shaft. Thus, the ball defect produces higher vibration when compared to inner race and outer race defects. The signals obtained from the ball defect of single, double and multiple defects in the ball bearing are measured in a consecutive manner. Vibration signals varies with increase in depth of the defect in ball defect. The Figure 7 shows the peak of the vibration is obtained for the ball defect with $0.5,1$ and $2 \mathrm{~mm}$ size as it reaches $238 \mathrm{mV}$. The vibration signal value of single defect in ball of the bearing is lies on 80 $\mathrm{mV}$. The value for the combination of the double defects ranges between $108 \mathrm{mV}$ to $171 \mathrm{mV}$. The vibration signal value for the three defects on the inner race is in between $152.4 \mathrm{mV}$ to $238 \mathrm{mV}$.

Finally, the Table 2 gives the complete classification of defects on different location by varying the depth to different rates such as gradually rising from $0.5 \mathrm{~mm}, 1 \mathrm{~mm}$ and $2 \mathrm{~mm}$. It shows the minimum and maximum range of amplitude values based on single, double and multi defects on the inner, outer race and ball of the bearings.

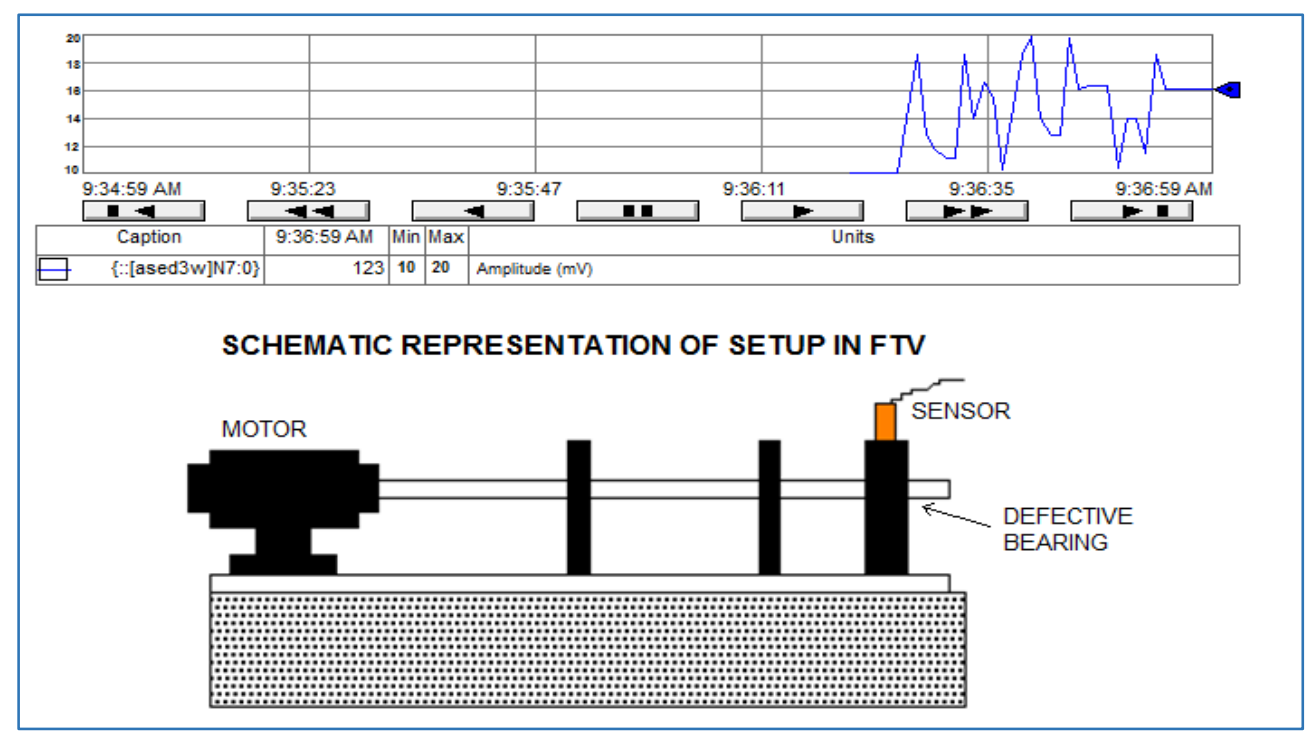

Figure 8. HMI screen with trend view of the experimental setup 


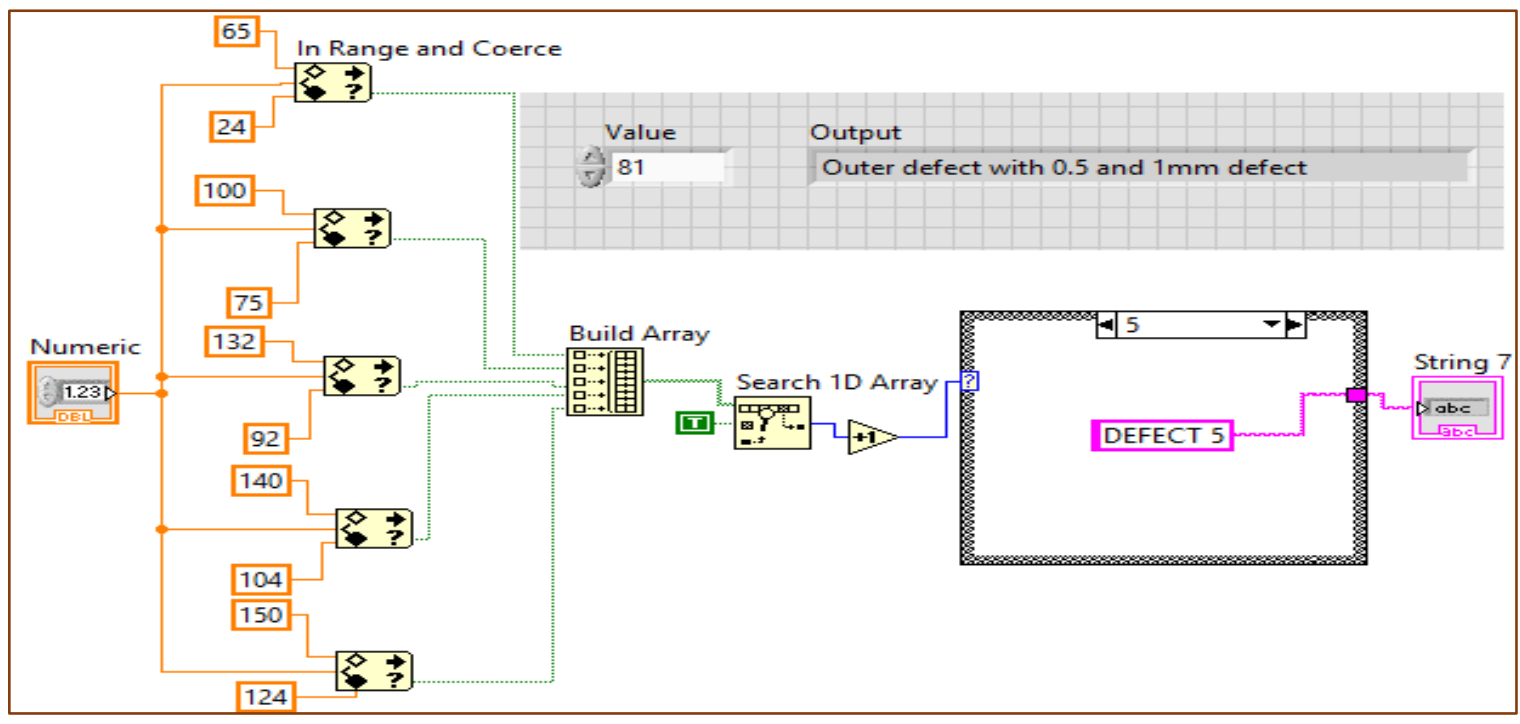

Figure 9. Identification of kind of defects in the ball bearing using LABVIEW

Table 2. Experimentation results of amplitude values of the defects in the ball bearings

\begin{tabular}{ccccc}
\hline Defect locations & \multicolumn{3}{c}{ Defect depths } & Min- Max range \\
& $0.5 \mathrm{~mm}$ & $1 \mathrm{~mm}$ & $2 \mathrm{~mm}$ & \\
\hline Inner race & $63.5 \mathrm{mV}$ & $69.8 \mathrm{mV}-140.8 \mathrm{mV}$ & $147.2 \mathrm{mV}$ & $63.5 \mathrm{mV}$ to $147.2 \mathrm{mV}$ \\
Outer race & $66 \mathrm{mV}$ & $75 \mathrm{mV}-161 \mathrm{mV}$ & $196 \mathrm{mV}$ & $66 \mathrm{mV}$ to $196 \mathrm{mV}$ \\
Balls & $152.4 \mathrm{mV}$ & $108 \mathrm{mV}-171 \mathrm{mV}$ & $238 \mathrm{mV}$ & $152.4 \mathrm{mV}$ to $238 \mathrm{mV}$ \\
\hline
\end{tabular}

\section{FAULT IDENTIFICATION THROUGH DATA LOGGING AND ONLINE MONITORING}

Factory Talk view software is a flexible HMI program that provides machine-level operator interface devices with a dedicated and efficient solution. The data logging of accelerometer sensor readings was acquired through PLC supported with Factory Talk view. The HMI developed for the experimental setup with trend view is shown in Figure 8.

The signals obtained for single, double and multi defects of the ball bearing are compared and their minimum and maximum values are noted. By considering these minimum and maximum values a front panel is created using LabVIEW and this helps to find the types of defect size and location in the bearing. This block diagram consists of build array, search 1D array and case structure in LabVIEW. These tools are enabled to classify the defective signal with responds to historical vibration signals. Hence vibration signals vary with increase in defected size of the bearing. Figure 9 shows the block diagram for identifying the type of defect in the bearing. When the values from the sensor is given, the values are compared with the historical values and the range in which the values lie gives a signal to the build array. This signal triggers the respective case structure and the case structure shows the kind of defect occurred in the bearing.

\section{CONCLUSIONS AND FUTURE SCOPE}

From this research work, the experimental analysis reveals that the size and location of the defect on the ball Bering plays major predominant role in the fault identification and diagnosis. In the real-time experimentation, it is inferred that the amplitude of the vibration signals gets increased when the count and size of the defects on the bearing gets increased. On comparing the inner, outer race bearing defects, the ball bearing exhibits higher vibration amplitude values, since it rolls continually in between the race. The obtained numerical statistics results show that the good bearing vibration amplitude values lies within the $10 \mathrm{mV}$ to $16 \mathrm{mV}$. Using data logging method in HMI incorporated with PLC, historical data of vibration signals were recorded. For the identification of defects in the bearing automatically, LABVIEW based monitoring system is developed. It is developed by incorporating array structure in which the single defect, double defect and multi defects amplitude values with location basis is updated. When the signal is received from the sensor, it compares the values in the database and executes autocorrelation to match with the most opt solution to display the kind of defects. For the inner race defect the maximum and minimum range hold between $63.5 \mathrm{mV}$ to $147.2 \mathrm{mV}$, for the outer race $66 \mathrm{mV}$ to $196 \mathrm{mV}$ and as final for ball defects its within $152.4 \mathrm{mV}$ to $238 \mathrm{mV}$. It is evident that the depth of the defect provides major contribution, hence when the defect is identified and rectified simultaneously automatically the bearing defect rate will be automatically reduced upon analyzing count and location of the defects on the ball bearings.

There is a lot of future scope in the structural analysis of ball bearing. The vibration signal provides good results for the combination of defect size of the bearing. The analysis can be further carried out for testing the ball bearing running at various speed and with various load acting on it.

\section{REFERENCES}

[1] Luo, S., Cheng, J. (2017). VPMCD based novelty detection method on and its application to fault identification for local characteristic-scale decomposition. Cluster Computing, 20(4): 2955-2965. 
https://doi.org/10.1007/s10586-017-0932-2

[2] Cao, H., Fan, F., Zhou, K., He, Z. (2016). Wheel-bearing fault diagnosis of trains using empirical wavelet transform. Measurement, 82: 439-449. https://doi.org/10.1016/j.measurement.2016.01.023

[3] Cerrada, M., Sánchez, R.V., Li, C., Pacheco, F., Cabrera, D., de Oliveira, J.V., Vásquez, R.E. (2018). A review on data-driven fault severity assessment in rolling bearings. Mechanical Systems and Signal Processing, 99: 169-196. https://doi.org/10.1016/j.ymssp.2017.06.012

[4] Cong, F., Chen, J., Dong, G., Pecht, M. (2013). Vibration model of rolling element bearings in a rotor-bearing system for fault diagnosis. Journal of Sound and Vibration, 332(8): 2081-2097. https://doi.org/10.1016/j.jsv.2012.11.029

[5] Kiral, Z., Karagülle, H. (2003). Simulation and analysis of vibration signals generated by rolling element bearing with defects. Tribology International, 36(9): 667-678. https://doi.org/10.1016/S0301-679X(03)00010-0

[6] Liu, J., Shao, Y., Lim, T.C. (2012). Vibration analysis of ball bearings with a localized defect applying piecewise response function. Mechanism and Machine Theory, 56: 156-169. https://doi.org/10.1016/j.mechmachtheory.2012.05.008

[7] Ma, J., Wu, J., Wang, X. (2018). Incipient fault feature extraction of rolling bearings based on the MVMD and Teager energy operator. ISA transactions, 80: 297-311. https://doi.org/10.1016/j.isatra.2018.05.017

[8] Maheswari, C., Priyanka, E.B., Meenakshipriya, B. (2017). Fractional-order $\operatorname{PI} \lambda D \mu$ controller tuned by coefficient diagram method and particle swarm optimization algorithms for $\mathrm{SO}_{2}$ emission control process Proceedings of the Institution of Mechanical Engineers, Part I: Journal of Systems and Control Engineering, 231(8): 587-599. https://doi.org/10.1177/0959651817711626

[9] Patel, V.N., Tandon, N., Pandey, R.K. (2014). Experimental study for vibration behaviors of locally defective deep groove ball bearings under dynamic radial load. Advances in Acoustics and Vibration, 2014: 1-7. https://doi.org/10.1155/2014/271346

[10] Priyanka, E.B., Subramaniam, T. (2018). Fuzzy logic forge filter weave pattern recognition analysis on fabric texture. International Journal of Electrical and Electronic Science, 5(3): 63-70.

[11] Priyanka, E.B., Maheswari, C., Thangavel, S. (2018). IoT based field parameters monitoring and control in press shop assembly. Internet of Things, 3: 1-11. https://doi.org/10.1016/j.iot.2018.09.004

[12] Priyanka, E.B., Maheswari, C., Thangavel, S. (2018). Online monitoring and control of flow rate in oil pipelines transportation system by using PLC based Fuzzy-PID Controller. Flow Measurement and Instrumentation, 62: 144-151. https://doi.org/10.1016/j.flowmeasinst.2018.02.010

[13] Priyanka, E.B., Maheswari, C., Thangavel, S. (2019). Remote monitoring and control of LQR-PI controller parameters for an oil pipeline transport system. Proceedings of the Institution of Mechanical Engineers, Part I: Journal of Systems and Control Engineering, 233(6): 597-608
[14] Priyanka, E.B., Krishnamurthy, K., Maheswari, C. (2016). Remote monitoring and control of pressure and flow in oil pipelines transport system using PLC based controller. In 2016 Online International Conference on Green Engineering and Technologies (IC-GET), IEEE, pp. 1-6. https://doi.org/10.1109/GET.2016.7916754

[15] Priyanka, E.B., Maheswari, C., Thangavel, S. (2018). Proactive decision making based iot framework for an oil pipeline transportation system. In International conference on Computer Networks, Big data and IoT, Springer, Cham, pp. 108-119. https://doi.org/10.1007/978-3-030-24643-3_12

[16] Sawalhi, N., Randall, R.B. (2011). Vibration response of spalled rolling element bearings: Observations, simulations and signal processing techniques to track the spall size. Mechanical Systems and Signal Processing, 25(3): 846-870. https://doi.org/10.1016/j.ymssp.2010.09.009

[17] Singh, S., Köpke, U.G., Howard, C.Q., Petersen, D. (2014). Analyses of contact forces and vibration response for a defective rolling element bearing using an explicit dynamics finite element model. Journal of Sound and Vibration, 333(21): 5356-5377. https://doi.org/10.1016/j.jsv.2014.05.011

[18] Priyanka, E.B., Maheswari, C., Thangavel, S., Bala, M.P. (2020). Integrating IoT with LQR-PID controller for online surveillance and control of flow and pressure in fluid transportation system. Journal of Industrial Information Integration, 17: 100127. https://doi.org/10.1016/j.jii.2020.100127

[19] Priyanka, E.B., Maheswari, C., Thangavel, S. (2020). A smart-integrated IoT module for intelligent transportation in oil industry. International Journal of Numerical Modelling: Electronic Networks, Devices and Fields, e2731. https://doi.org/10.1002/jnm.2731

[20] Priyanka, E.B., Maheswari, C., Meenakshipriya, B. (2016). Parameter monitoring and control during petrol transportation using PLC based PID controller. Journal of Applied Research and Technology, 14(2): 125-131. https://doi.org/10.1016/j.jart.2016.03.004

[21] Priyanka, E.B., Maheswari, C., Ponnibala, M., Thangavel, S. (2019). SCADA based remote monitoring and control of pressure \& flow in fluid transport system using IMC-PID controller. Advances in Systems Science and Applications, 19(3): 140-162. https://doi.org/10.25728/assa.2019.19.3.676

[22] Subramaniam, T., Bhaskaran, P. (2019). Local intelligence for remote surveillance and control of flow in fluid transportation system. Advances in Modelling and Analysis C, 74(1): 15-21. https://doi.org/10.18280/ama_c.740102

[23] Wang, H.Q., Hou, W., Tang, G., Yuan, H.F., Zhao, Q.L., Cao, X. (2014). Fault detection enhancement in rolling element bearings via peak-based multiscale decomposition and envelope demodulation. Mathematical Problems in Engineering, 2014: 1-11. https://doi.org/10.1155/2014/329458

[24] Zakhezin, A.M., Malysheva, T.V. (2010). Vibration diagnostics of fatigue cracks. Journal of Machinery Manufacture and Reliability, 39(2): 185-190. https://doi.org/10.3103/S1052618810020147 